\title{
Maria Antonia
}

\section{a interrogação sobre um lugar a partir da dor}

\author{
IRENE DE ARRUDA RIBEIRO CARDOSO
}

\begin{abstract}
RESUMO: A partir da idéia de que a dor possa se constituir numa interrogação pertinente na história, pretende-se pensar a Maria Antonia como um lugar objeto de construções na memória, de pontos de vista nostálgicos. A tematização da temporalização do lugar, dos diferentes tempos nele implicados - o que leva a considerá-lo como não preformável ou predeterminável - permitirá explorá-lo a partir de dois modos de acontecer nostálgico: a "nostalgia aberta" e a "nostalgia fechada". O que caracteriza esta última é fundamentalmente o retorno, entendido como um congelamento do tempo (o passado), ou uma retenção do tempo. A nostalgia aberta, ao implicar numa desfamiliarização em relação a um lugar, aponta para a possibilidade de uma temporalização da atualidade em que o passado se inscreve no presente, permitindo as reversões de ponto de vista.
\end{abstract}

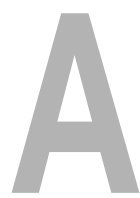

possibilidade de construção deste lugar chamado Maria Antonia parte inevitavelmente da memória ou das memórias que dela se tem. Memória difícil, não a memória tranqüila, de um espaço que, no ano convulso e vertiginoso de 1968, foi fisicamente destruído, interditado e incendiado num anoitecer, e que na imaginação dos "retirantes" que contaram e ouviram a história - como relata Aziz Simão - transformouse no "espaço mítico" onde o "fogo criminoso transmutou-se em fogo ritual de sua mitificação" (Simão, 1988, p.18).

Não há como não partir das memórias de um espaço sobre o qual se tentou lançar o esquecimento, sob a forma primeira do interdito e depois sob a forma da dispersão no tempo, para a partir delas tentar a reconstrução do que é que precisava ser esquecido, simbolicamente queimado, abandonado, na retirada compulsória que caracteriza todo exílio político.
UNITERIMOS

Maria Antonia,

tempo,

memória,

dor,

nostalgia.

Texto originalmente apresentado no Colóquio Arte-Dor, organizado pelo Instituto de Psicologia da USP em maio de 1995.

Professora do Departamento de Sociologia da FFLCH-USP 
A Maria Antonia é um daqueles espaços marcados pela condição do exílio, de um exílio que já se constitui na dor da partida.

O material de que se dispõe, embora não tão extenso, é, no entanto, bastante expressivo enquanto registro dessa memória. Se não é completo mas quando é que a memória se completa? - evidencia alguns traços significativos desse lugar chamado Maria Antonia ${ }^{1}$.

Estas memórias têm em comum, no que se refere ao espaço da Maria Antonia, o fato de se constituírem em diferentes nominações que produzem diferentes lugares da memória. Nessa medida, "nomear", como mostra Pierre Fédida, envolve uma "atividade de percepção" em que o visual é "menos uma forma de espacialização que a condição de uma figuração" (Fédida, 1991, p. 78).

As memórias, através das nominações, descongelam o espaço inominado, temporalizando este espaço a partir da atualidade, produzindo assim os diferentes lugares, através do seu poder de figuração.

É possível então construir a interrogação: o que é este lugar chamado Maria Antonia, na memória dos retirantes-exilados? Quais seriam as diferentes figurações que toma esse lugar?

Nesses registros da memória, esses lugares produzidos pelo trabalho interrogativo da rememoração, tomam diferentes figurações: a questão quem era a Maria Antonia, constrói a figuração da pessoa ou da personalidade; a questão o que era a Maria Antonia constrói as figurações da encruzilhada, da praça, do saguão, de uma escola, de um pensamento, de um sentimento, de uma paixão, do desejo, de uma razão política, de um modo de ser e de existir, de uma ausência, da vida e da morte, do inconclusivo.

Essas figurações dos lugares podem ser aqui recolhidas a partir dos registros da memória, a partir de um saber interrogativo. Essa reconstrução pode ser elaborada na forma de perguntas, pois "um pensamento não é hoje capaz de outro passo que não seja meditar insistentemente sobre aquilo que suscitam as interrogações levantadas" (Heidegger, 1969, p. 38).

Quem era a Maria Antonia? Uma pessoa?

É desse modo que aparece no depoimento de Maria Adélia de Souza o seguinte diálogo reconstruído:

“- Mãe, hoje não volto para casa, vamos tomar a faculdade e eu vou dormir na Maria Antonia.

- Filha, essa é uma amiga que não conheço. Deixe o telefone dela, qualquer coisa... Engraçado, a Maria Antonia jamais esteve aqui em casa... - Maria Antonia... Que intimidades, que carinho, que saudades" (Souza, 1988, p. 103).

1 Referência ao conjunto de textos e depoimentos do livro organizado por Maria Cecília Loschiavo dos Santos (1988). nda deste modo que Renato Pompeu reconstrói a Maria Antonia:

"A Maria Antonia para mim não é apenas uma rua onde ficava uma faculdade; na verdade para mim ela se personaliza e então a Maria Antonia para mim 
é uma moça, uma moça bem jovem, bonita, inteligente, sedutora, rica, porém irremediavelmente louca” (Pompeu, 1988, p. 114).

Por que mulher? "se havia algum lugar em que a mulher era importante em termos de ser igual ao homem, era a Maria Antonia. Portanto, a Maria Antonia tinha realmente de ser uma mulher" (Pompeu, 1988, p. 114).

Por que jovem? "a Filosofia como faculdade era bem nova [...] principalmente em termos de novidade, mesmo como conteúdo e forma de ensino [...]. A Maria Antonia surgia como fator de modernização" (Pompeu, 1988, p. 114).

Por que bonita e sedutora? "a Maria Antonia não queria só encantar e agradar [era extremamente agradável ao olhar], ela queria conquistar, angariar apoio para a sua causa" (Pompeu, 1988, p. 114).

Por que rica? Porque embora havendo os cursos noturnos, "os alunos da Maria Antonia no curso diurno se destacavam [intelectual e politicamente] pela quase total despreocupação quanto às necessidades da sobrevivência" (Pompeu, 1988, p. 115).

Por que inteligente? era uma moça "inteligente", de "inteligência excepcional" porque sua "situação na sociedade, de parte da classe dominante porém com ligações com a classe dominada, lhe permitia ter uma visão ampla da sociedade, o que não era facultado nem ao grosso das classes dominantes nem ao grosso das classes dominadas". Por isso a "Maria Antonia também ficava desligada do real, porque nessa situação de fronteira, ela não tinha responsabilidades concretas [...] sobrando-lhe portanto um espaço em que tudo se passava apenas no pensamento" (Pompeu, 1988, p. 115-116).

"E aqui entra a loucura da Maria Antonia". Por que louca?

"Sobrando-lhe socialmente esse espaço de puro pensamento, ela já não raciocinava a partir do real concreto [...]. A Maria Antonia raciocinava a partir das puras constatações pensadas [...] a partir do livre movimento do puro pensamento. E assim chegou à conclusão de que a situação era mais avançada do que efetivamente era. Na situação concreta da ditadura militar foi assim fácil à Maria Antonia chegar à conclusão de que a saída era luta armada ou a frente de esquerda [...].

Hoje podemos dizer que os herdeiros da Maria Antonia são menos ricos, menos bonitos e menos inteligentes, porém continuam igualmente loucos e sedutores. [...] loucos pois lhes sobra um espaço mais do pensamento puro do que de inserção concreta na sociedade, sedutores, pois pregam que para se chegar a uma sociedade ideal, basta ter a vontade disso, sem levar em conta as situações materiais da sociedade. 
É isso que constitui para mim a Maria Antonia, que não existe mais em carne, porém continua existindo em espírito" (Pompeu, 1988, p. 116-117).

O que era a Maria Antonia? Por que um "saguão", uma "praça", uma "escola", uma "encruzilhada"? Segundo o relato de Aziz Simão, a Maria Antonia era o seu "saguão" - "praça fervilhante da manhã à noite" [...] "uma encruzilhada onde se conversava no meio de um vaivém de gente chegando e indo, subindo e descendo as escadas, entrando e saindo das salas" (Simão, 1988, p. 15).

Foi uma escola - "um lugar para as vocações que não tinham lugar" - o lugar de uma "expansão do saber que se processou de certo modo revolucionário em nosso quadro cultural da época" e uma "faculdade em mudança, cujos efeitos não se restringiram ao âmbito curricular, extravasando para o político" (Simão, 1988, p.14-15).

O que era a Maria Antonia? Por que "lugar do pensamento"? Da "amizade"? Das "paixões amorosas"? Da "paixão política"? Ou da "razão política"?

A Maria Antonia era um lugar onde estava inscrito um dos lemas de 68: "sejamos realistas - peçamos o impossível" (Chauí, 1988, p. 250). Era também o lugar do pensamento, pois a Maria Antonia "significou um novo estilo de pensamento formado a partir da Faculdade de Filosofia, Ciências e Letras - FFLCH/USP"(Gianotti, 1988, p. 44).

Mas a Maria Antonia significou um lugar onde os contatos eram "face a face". "Nossos amigos e nossos amores, tudo girava em torno daquele pessoal da Maria Antonia" (Gianotti, 1988, p. 45).

"A Maria Antonia não foi uma rua de São Paulo. Foi, a Maria Antonia uma instituição política [...], do aprendizado da História do Brasil, da resistência e do amor" (Souza, 1988, p. 105).

A Maria Antonia foi um "reduto da resistência cultural. [...]. Sim, houve ingenuidade e até inconseqüência na euforia revolucionária de 68. Mas o que sobretudo permaneceu foi a crispação da vontade de dizer 'não' à miséria das circunstâncias" (Moraes, 1988, p. 112-113).

Por que a Maria Antonia era um "modo de existir", um "modo de ser", o "lugar do desejo", o "lugar do inconclusivo", o "lugar da morte"?

Um modo de existir, um modo de ser? Na Maria Antonia, "cada qual julgava dever transformar-se exatamente para que as idéias que discutia e propagava não fossem apenas idéias; cada um julgava que a participação política na transformação do mundo exigia viver concretamente os valores que propunha. A consciência crítica somente seria real se fosse vital" (Silva, 1988, p. 134).

"Era, pois, como se cada um vivesse na instabilidade constante de uma descoberta progressiva de si, que se fazia no jogo da identificação e da contraposição, 
em relação aos outros e às idéias.

[...] numa época e num lugar em que inexistiam fronteiras entre o saber acadêmico e a vida ordinária, entre o conhecimento e a conduta, era talvez natural que se considerassem mais próximos entre si as idéias e as coisas, os ideais e a realidade. A universidade não era uma interferência na vida dos universitários; era um meio de existir, uma razão de ser e de pensar. Não é por acaso que aqueles que lá viveram dizem, indiferentemente, a faculdade ou a Maria Antonia, pois a instituição se prolongava física e espiritualmente na trindade etílica constituída pelo Cientista, pelo Bar do Meio e pelo Bar do Zé, angulando ainda para parte do edifício que vizinhava, na Rua Dr. Vila Nova, com o Bar Sem Nome (Silva, 1988, p. 135).

"inconclusivo"?

O lugar do "desejo", o lugar da "vida e da morte" - o lugar do

Falar da Maria Antonia é falar daquele prédio cinzento e desenxabido, com o mau gosto das colunas gregas timbrando em realçar a sua entrada principal. Necessidade de evocar o lugar, para convocar a força do lugar [...] eu diria que aqueles que viveram na Maria Antonia naquela época, se põem nessa atitude: a procura de um espaço-tempo em que as coisas aconteciam” (Menezes, 1988, p. 120).

"A dificuldade maior é a de encontrar o sentimento generalizado de se ter sido protagonista daquela história. E esse sentimento é, por um lado, o de realização de idéias e desejos e por outro, de perdaseparação e morte. A Maria Antonia foi marcada em 1968 por imagens de vida e de morte, tão radicalmente contrárias: a 'alegria de viver' e a 'sorte de viver" (Cardoso, 1988, p. 232).

"Houve a ação violenta daqueles que usurparam lugares na história, o que nos impede de lembrar a Rua Maria Antonia com a tranqüilidade com que se concede, na memória um lugar àquilo que passou. Pelo contrário, aqui a memória sofre o desconforto da incompletude como se lembrar fosse presentificar a ausência, procuraro vazio ou contemplar uma morte prematura. [...] resta apenas a memória retorcida ante o inconclusivo e o sentimento - como estranho afeto suspenso no ar - da perda do irrealizado (Silva, 1988, p. 136). 
Estas reconstruções, aqui recortadas, porém inesgotáveis, constituem os lugares da memória - lugares não pré-formáveis ou pré-determináveis. A Maria Antonia como um daqueles espaços marcados pela condição do exílio, como apontou-se inicialmente, é por isso também marcada pelo acontecer nostálgico.

E aqui a nostalgia não é entendida como uma algia, de algos-dor, inteiramente imotivada nem inteiramente indeterminada. Alguma coisa se sabe ou se pressente. Esta dor não permanece muito tempo sem ser nomeada. Esta dor pode dizer do que ela sofre, do que ela é o mal; ela é, como em toda condição de exílio, o mal de um país, o mal de uma origem, o mal de uma fonte, que se busca reencontrar. A possibilidade deste reencontro é o retorno, nostos.

Mas a nostalgia (nostos-retorno-algos-dor) está referida a um "espaço nostálgico" onde os "lugares não são intercambiáveis e indiferentes, como eles deveriam ser no espaço abstrato e homogêneo dos geômetras". Porque a "geometria não tem nada a ver com a nostalgia... É para os matemáticos que todo lugar vale um outro; e é o contrário para o coração nostálgico, em que existe um espaço concreto, diversificado por sítios, [lugares] qualitativamente heterogêneos"(Jankélévitch, 1974, p. 341).

É deste modo que podemos considerar a nostalgia como um tipo de memória, como um trabalho de reminiscência e de imaginação, que pela sua força de evocação, fabrica, produz, os lugares da memória.

E aqui seria preciso distinguir, redimensionando os conceitos, a "nostalgia fechada" da "nostalgia aberta" (cf. Jankélévitch, 1974, p. 349-352 e 360-367).

$\mathrm{Na}$ "nostalgia fechada" o retorno anularia, sem resto, o expatriamento, ou formulando de um outro modo, se caracterizaria por um congelamento do tempo, uma retenção do tempo. Nesse sentido, seria próximo da melancolia, na definição que dela formula Julia Kristeva: fixada ao "passado, regressando ao paraíso ou ao inferno de uma experiência não ultrapassável", a melancolia "é uma memória estranha" — tudo findou, mas permanece fiel a esta coisa finda, está colada a ela, não há futuro, pois é "um passado hipertrofiado, ocupa todas as dimensões [...]" (Kristeva, 1989, p. 61).

$\mathrm{Na}$ "nostalgia aberta", a memória é um acontecer nostálgico; enquanto força de evocação e de produção de lugares e de figurações, a força de nominação, não é uma força que fixa mas uma força que imprime um tornarse, produtora de mudanças de lugares, que são também mudanças de tempo. Nesse sentido, o passado anacroniza-se.

O que caracteriza a "nostalgia aberta" é que aí o retorno tem um resto. Na formulação de Jankélévitch, o retorno é o encontro com uma "decepção", com um "desapontamento", o que o torna um "retorno infinito", que faz do "país", da terra natal, da origem, da fonte, o lugar de um desejo indeterminado, em que esta origem, esta fonte, este país, seriam apenas a "localização simbólica e metafórica" deste desejo indeterminado. O retorno 
aqui é uma etapa de um caminho para um outro lugar não nomeado, um outro lugar, em relação ao qual ninguém jamais disse, nem o lugar, nem o tempo, nem o nome - um lugar... que não é o termo final, "mas o ponto de partida de uma nova aventura"(Jankélévitch, 1974, p. 363).

Pode-se dizer que o sentido desse retorno é o de um segundo exílio: ao primeiro exílio da partida, segue-se o segundo exílio a partir do não reencontro, no retorno.

Nessa condição de segundo exílio, a nostalgia aberta é um lamentar uma ausência, o que não está presente. Jankélévitch encontra no termo platônico pótos aquele que designa simultaneamente o lamento pelo ausente e o desejo, assim como a palavra latina desiderium é desejo e lamento pelo ausente, que pode ser traduzido na língua portuguesa por saudades (termo aliás referido no texto de Jankélévitch, cf. 1974, p. 366-367).

O termo platônico pótos como um desejo pelo ausente, ou como um desejo a partir do ausente encontra no Banquete a seguinte formulação: quando não se crê que alguma coisa falta, não se deseja (cf. Platão, 1945, 204d).

Nesse sentido, o retorno aqui não é um passo atrás na descoberta de uma origem, um regresso às fontes, mas um "retorno adiante", o deixar que as fontes nos retornem².

E aqui é preciso então construir esse sentido: a "nostalgia aberta" é um tipo de memória que produz os "lugares da memória" a partir da dor. A dor (algos) é entendida aqui como "aquilo que recolhe no mais íntimo", na formulação de Heidegger. Este, refletindo sobre "a palavra grega que exprime a dor-algos", diz: "provavelmente algos se liga etimologicamente a alego, que enquanto forma intensiva de lego, significa o íntimo recolher. Então a dor seria aquilo que recolhe no mais íntimo" (Heidegger, 1969, p. 37).

Mas o recolher é também o que caracteriza a memória para Heidegger. A memória é a "lembrança recolhida", a "reunião do pensamento", "o recolher do já pensado", do que é preciso considerar antes de tudo "como sendo ou tendo sido"(cf. Heidegger, 1958, p. 161 e 164-165). A memória é aqui uma memória "atraída pelo que se reserva e pelo que se pode impor a nós como o que merece ser esperado: esperar quer dizer aqui aguardar por todos os lados, no interior do já pensado, o não pensado ainda que aí se esconde" (Figueiredo, 1994, p. 111).

O retorno da "nostalgia aberta", não como retorno às origens, ou às fontes, mas como um "retorno adiante", o "deixar que as fontes nos retornem", significa que o segundo exílio, é o exílio de um mundo que só o pensamento pode guardar e aguardar, como memória, como reserva do já pensado e como espera do não pensado ainda.

E neste ponto podemos retornar à Maria Antonia: podemos talvez dizer que as diferentes figurações dos lugares produzidas pela memória, anteriormente marcadas - um lugar personalizado, um lugar da paixão amorosa, um lugar da paixão política, um lugar do pensamento, um lugar da encruzilhada,
2 Nasio, Juan David, comentando o poema "Retorno", de Hölderlin, a partir de Heidegger. (1991, p. 28-29).

3 Cf. também Heidegger (1958, p. 161 e 164$165)$. 
um lugar da realização de idéias e desejos, um lugar da vida e da morte, um lugar do inconclusivo - estavam referidos a uma certa atitude, a uma certa maneira de relacionar-se com o mundo, a uma maneira de pensar e de sentir, a uma forma de atuar e conduzir-se. Ao que poderíamos chamar, ainda de um modo enigmático, um certo ethos, da Maria Antonia. E esse ethos tinha um traço comum, nas figurações dos lugares produzidos pela memória. Era o de uma atitude de se colocar no limite do seu tempo e na perspectiva de transgredilo (cf. Foucault, 1988).

Esta memória, da "nostalgia aberta", que no movimento da atualização re-colhe esse traço comum, que re-úne o que se colheu, pode com-preender simultaneamente duas finitudes históricas: a primeira, que comportou esse ethos até um determinado limite, não ultrapassável, e que levou àquilo que chamamos de primeiro exílio; a segunda, inscrita no hoje, caracterizada pela "atravancadora cotidianidade" (Jankélévitch, 1974, p. 347) das tarefas imediatas, dos planejamentos e dos produtivismos a partir da qual se realiza o segundo exílio, na decepção causada pelo não re-encontro, e pela perspectiva do retorno infinito e do desejo indeterminado.

A "nostalgia aberta" como movimento da atualização que retém e atende (no sentido da espera), e enquanto movimento da memória, do pensamento, que instaura as mudanças de lugares, que são também mudanças no tempo - deslocamentos no tempo - pode pensar, problematizar o tempo presente, como crítica do hoje que pode ser entendida simultaneamente como uma análise histórica, dos limites que se nos impõem e como experimento que torna possível ultrapassá-los, na formulação foucaultiana da "problematização" (cf. Foucault, 1988) e na formulação heideggeriana do "experimento", como experiência que consiste em deixar que algo venha sobre nós e nos faça outro (cf. Figueiredo, 1994, p. 121).

Rececebido para publicação em julho/1996 
CARDOSO, Irene de Arruda Ribeiro. Maria Antonia - a interrogação sobre um lugar a partir da dor. Tempo Social; Rev. Sociol. USP, S. Paulo, 8(2): 1-10, outubro de 1996.

CARDOSO, Irene de Arruda Ribeiro. Maria Antonia - a questioning about a place starting from pain. Tempo Social; Rev. Sociol. USP, S. Paulo, 8(2): 1-10, october 1996.

ABSTRACT: Based on the idea that pain can constitute a permanent questioning in history, the aim of this paper is to think about Maria Antonia as a place which is an object of memory constructions, of nostalgic points of view. Focusing the temporalities of the place, the different times it implies what leads to consider it as not prefashionable or predeterminable - makes it possible to explore the place starting from two nostalgic ways of happening: the "open nostalgia" and the "closed nostalgia". What characterizes the latter is mainly the return, understood as a freezing of time (the past), or a redemption of time. The open nostalgia, implying a defamiliarization with regard to a place, points out to the possibility of a temporalization of the actuality in which the past inscribes itself in the present, allowing changes of viewpoints.

\section{REFERÊNCIASBIBLIOGRÁFCAS}

Cardoso, Irene de Arruda Ribeiro (1988) Os acontecimentos de 1968 - notas para uma interpretação. In: SANTos, Maria Cecília Loschiavo (org.). Maria Antonia: uma rua na contramão. São Paulo, Nobel.

CHAUí, Marilena. (1988) Um lugar chamado Maria Antonia. In: SANTOS, Maria Cecília Loschiavo (org.). Maria Antonia: uma rua na contramão. São Paulo, Nobel.

FÉDIDA, Pierre. (1991) Nome, figura e memória - a linguagem na situação psicanalítica. Trad. Martha Gambini \& Cláudia Berliner. São Paulo, Escuta.

FigueIREdo, Luis Cláudio. (1994) Escutar, recordar, dizer: encontros heideggerianos com a clínica psicanalítica. São Paulo, Escuta/ Educ.

FouCAUlt, Michel. (1988) Que es la ilustración? (Was ist Aufklärung?). Versão de Rebeca Trevinho. Sociologica. Mexico, Universidad Autonoma Metropolitana, ano 3, n⿳0 7-8, maio-deciembre.

GiAnotTI, José Artur. (1988) Maria Antonia: uma certa geração da Faculdade de Filosofia. In: SAntos, Maria Cecília Loschiavo (org.). Maria Antonia: uma rua na contramão. São Paulo, Nobel.

HeIDEGGER, Martin. (1958) Que veut dire 'penser'?. In: . Essais et conférences. Paris, Gallimard.

. (1969) Sobre o problema do ser. O caminho do campo. Trad. Ernildo Stein. São Paulo, Duas Cidades.

JankélÉvitch, Vladimir. (1974) L’irréversible et la nostalgie. Paris, Flammarion.

UNITERIMS:

Maria Antonia, time, memory, pain, nostalgia. 
Kristeva, Julia. (1989) Sol negro: depressão e melancolia. Trad. Carlota Gomes. Rio de Janeiro, Rocco.

Menezes, Adélia Bezerra de. (1988) Maria Antonia: década de 60. In: SANTos, Maria Cecília Loschiavo (org.). Maria Antonia: uma rua na contramão. São Paulo, Nobel.

MorAes, João Quartim de. (1988) Na Maria Antonia dos anos 60: a reforma da filosofia e a revanche dos golpistas. In: SANTos, Maria Cecília Loschiavo (org.). Maria Antonia: uma rua na contramão. São Paulo, Nobel.

NASIO, Juan David. (1991) A criança magnífica da psicanálise: o conceito de sujeito e objeto na teoria de Jacques Lacan. $2^{\mathrm{a}}$ edição. Trad. Dulce Duque Estrada. Rio de Janeiro, Zahar.

Platão. (1945) Le Banquet. Oeuvres complètes. Versão de E. Chambry. Paris, Librarie Garnier Frères, troisième tome, p. 21-86.

PoMPEU, Renato. (1988) Uma bela moça. In: SANTos, Maria Cecília Loschiavo (org.). Maria Antonia: uma rua na contramão. São Paulo, Nobel.

SAntos, Maria Cecília Loschiavo (org.). (1988). Maria Antonia: uma rua na contramão. São Paulo, Nobel.

Silva, Franklin Leopoldo e. (1988) Rua Maria Antonia. In: SAntos, Maria Cecília Loschiavo (org.). Maria Antonia: uma rua na contramão. São Paulo, Nobel.

SimÃo, Aziz. (1988) Na faculdade. In: SANTos, Maria Cecília Loschiavo (org.). Maria Antonia: uma rua na contramão. São Paulo, Nobel.

SouzA, Maria Adélia de. (1988) Rua Maria Antonia. In: SAntos, Maria Cecília Loschiavo (org.). Maria Antonia: uma rua na contramão. São Paulo, Nobel. 